\title{
TREATMENT OF UNSTABLE THORACOLUMBAR FRACTURES IN PEDIATRIC PATIENTS
}

\author{
TRATAMIENTO DE FRACTURAS TORACOLUMBARES INESTABLES EN PACIENTES PEDIÁTRICOS
} TRATAMENTO DAS FRATURAS TORACOLOMBARES INSTÁVEIS EM PACIENTES PEDIÁTRICOS

Roberto Chapa Sosa', Edgar Rubén Urrutia Vega 1

\begin{abstract}
Objective: To analyze the characteristics of unstable thoracolumbar fractures in the pediatric population. Methods: A retrospective cross-sectional study was conducted with pediatric patients (0 to 15 years) who presented with unstable thoracolumbar fracture with or without neurological damage. Twenty-four operated patients were analyzed: 13 male and 11 female. Results: Falls from height are the most common cause, being the thoracolumbar junction the anatomical site most frequently injured. Conclusion: The thoracolumbar fractures are rare in the pediatric population, as well as post-surgical instrumentation structural deformities.
\end{abstract}

Keywords: Spine; Spine injuries; Child.

\section{RESUMO}

Objetivo: Analisar as características das fraturas toracolombares instáveis na população pediátrica. Métodos: Estudo transversal retrospectivo com pacientes pediátricos (0 a 5 anos) que apresentaram fratura toracolombar instável com e sem dano neurológico. Foram analisados 24 pacientes operados: 13 homens e 11 mulheres. Resultados: quedas de altura são a causa mais comum, sendo a junção toracolombar o local anatômico mais frequentemente atingido. Conclusão: As fraturas toracolombares são raras na população pediátrica, assim como as deformidades estruturais depois de instrumentação cirúrgica.

Descritores: Coluna vertebral; Traumatismos da coluna vertebral; Criança.

\section{RESUMEN}

Objetivo: Analizar las características de las fracturas toracolumbares inestables en la población pediátrica. Métodos: Se realizo un estudio transversal retrospectivo de pacientes pediátricos (0 a 15 años) que presentaron fractura toracolumbar inestable con y sin daño neurológico. Se analizaron 24 pacientes operados: 13 masculinos y 11 femeninos. Resultados: Las caídas de altura son la causa más común, siendo la unión toracolumbar el sitio anatómico más frecuentemente lesionado. Conclusión: Las fracturas toracolumbares son raras en la población pediátrica, así como las deformidades estructurales posteriores a la instrumentación quirúrgica.

Descriptores: Columna vertebral; Traumatismos vertebrales; Niño.

\section{INTRODUCTION}

Spinal cord injuries in children have increased in recent years, as a result of the diversity and increase in sports activities and in particular, the increasing numbers of automobile and motorcycle accidents.

Although thoracolumbar fractures are rare in children, ${ }^{1-6}$ the damage resulting from this type of injury is considerable, as these injuries can be irreversible, particularly when there is neurological damage, ${ }^{7}$ and there may also be damage to internal organs or intra-abdominal vascular structures, depending on the kinematics of the injury. ${ }^{8}$

Thoracolumbar fractures are more frequent in adolescents, the most common causes being falls from a height and motorcycle accidents. ${ }^{9}$ The diagnosis and treatment are different in the pediatric population, due to the intrinsic characteristics of the thoracolumbar spine in this age group. ${ }^{10}$

The aim of this study was to analyze unstable thoracolumbar fractures in the pediatric population ( $0-15$ years) of a highly specialized hospital, taking into account postsurgical progress, neurologic status, residual deformity and degree of function.

\section{MATERIAL AND METHODS}

A retrospective cross-sectional study was conducted with those pediatric patients ( 0 to 15 years) who presented with unstable thoracolumbar fracture with or without neurological damage, and who underwent open reduction and internal fixation of the thoracolumbar spine from 1994 to 2009. This study was approved by the ethics committee of the Mexican Institute of Social Security.

The study subjects were residents of the state of Nuevo Leon, Mexico, and as they were from a center of reference in the Northeast region of the country, the four neighboring states also included, as they too sent patients requiring highly specialized medical and surgical care.

The medical records were analyzed, taking into account demographics, the fractured vertebral anatomical levels, the classification of fractures according to the AO classification system (Arbeitsgemeinshaft für Osteosynsthesefragen), the injury mechanism, the pre and postoperative neurological status of the patient according to the ASIA (Standard Neurological Classification of Spinal Cord Injury of the American Spinal Injury Association) scale, and the internal fixation system used, as well as residual deformity and functional status.

Patients underwent surgery performed by orthopedic surgeons specialized in spinal surgery, and were subsequently evaluated in an outpatient visit.

Each patient was assessed before and after surgery using the ASIA (Standard Neurological Classification of Spinal Cord Injury of the American Spinal Injury Association) questionnaire.

Each patient underwent a radiographic assessment of their fracture (plain X-rays, computed axial tomography and nuclear magnetic resonance imaging) in order to plan their surgery.

1. IMSS - Unidad Médica de Alta Especialidad Número 21 
Fractures were classified by the $\mathrm{AO}$ (Arbeitsgemeinshaft für Osteosynsthesefragen) thoracolumbar fracture classification system, and the implants used varied according to the year in which the patients were operated.

\section{RESULTS}

Of a total of 24 patients with unstable fracture at the thoracolumbar level, the age bracket of the population studied was 0-17 years; the average age was 13.1 years; and the age group in which thoracolumbar fractures were most frequent was 9 to 14 years.

The study included 13 male patients and 11 female patients; males were affected the most by this pathology (69\%).

The most frequent mechanism of injury in our study was falls from heights; of more than 1.5 meters in $46 \%$ of our population (11 patients) and of more than 3 meters in $33 \%$ of our population (8 patients). Within the 1.5 meter range, falling from a shelf while painting and falling from a motorized vehicle while driving were most common, while those from more than 3 meters included a fall from the roof of a two-storey house. (Figure 1)

The types of injury that occurred in our population included thoracolumbar fracture of a single vertebral level, thoracolumbar fracture of more than 2 vertebral levels, and thoracolumbar fracture-dislocation. Thoracolumbar fracture of a single vertebral level was the most frequent.

In the patients who presented with thoracolumbar fracture-dislocation, the most frequently injured anatomical levels were vertebral levels T12-L1 (thoracolumbar junction: T12 thoracic vertebra number 12, L1: lumbar vertebra number 1) and lumbar levels L3-L4 (lumbar vertebra junction number 3-lumbar vertebra number 4). (Figure 2)

Among the patients with fractures by thoracolumbar vertebral level, the most common fracture site was lumbar vertebra number 1 (L1).

In patients who presented with fractures of more than two vertebral levels, the fractures were at the level of thoracic lumbar junction of vertebrae T12, L1 and L2 (T12: thoracic vertebra number 12, L1; lumbar vertebra number 1, L2: thoracic vertebra number 2).

In the AO fracture classification (Arbeitsgemeinshaft für Osteosynsthesefragen) the most common type of fracture was type B. (Figure 3)

In the pre-surgical assessment of neurological status in the ASIA classification, $71 \%$ had a neurological status rated ASIA E, $4 \%$ of patients had ASIA B status and $25 \%$ had a neurological status rated as ASIA C. (Figure 4)

Patients underwent surgery by open reduction and internal fixation via the posterior approach using transpedicular screws, with a total of eighty-four $5 \mathrm{~mm}$-screws inserted in 21 patients, as well as 12 pedicle hooks in 3 patients. Approximate bleeding was $110 \mathrm{cc}$. on average per surgery.

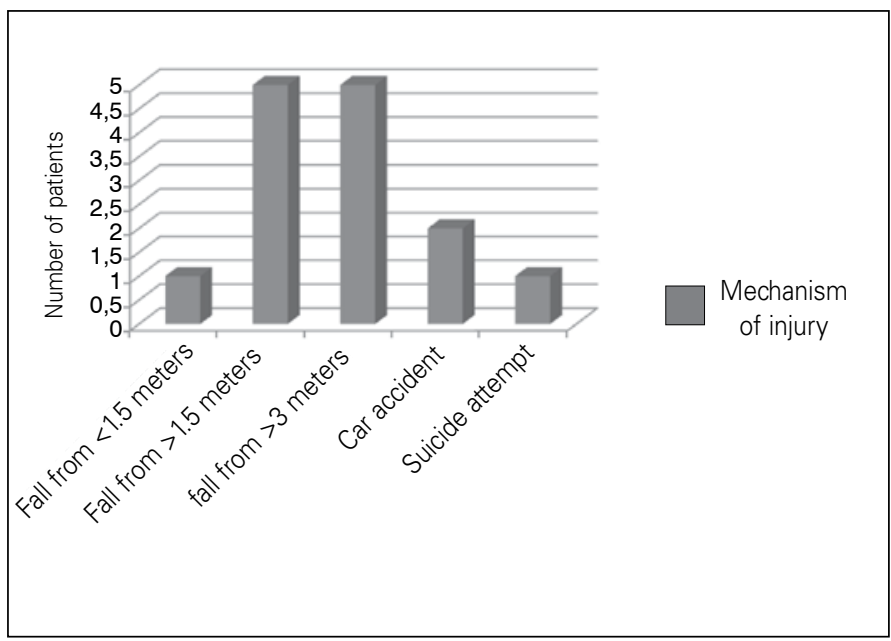

Figure 1. Mechanisms of injury of thoracolumbar fractures in the pediatric population.

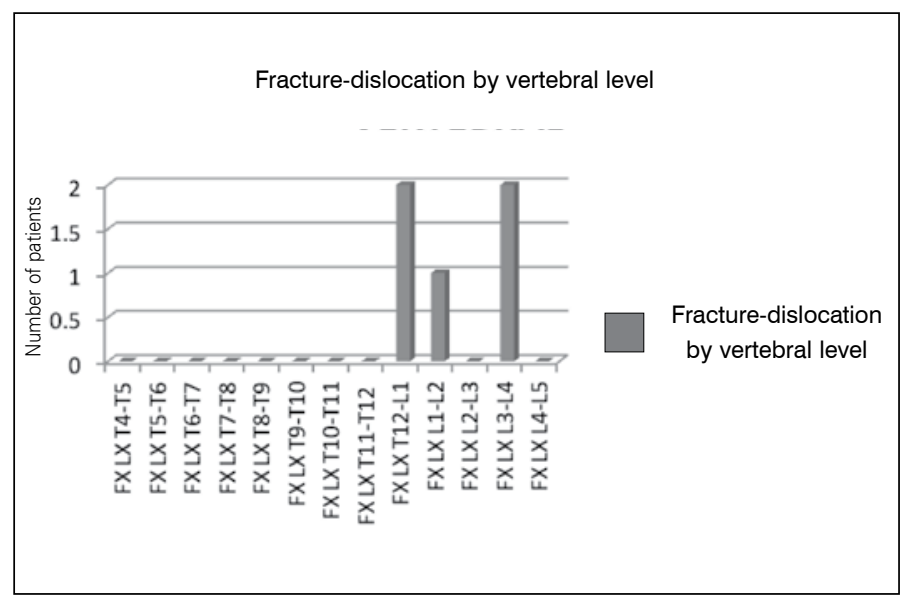

Figure 2. Anatomical levels affected in thoracolumbar fracture-dislocations in the pediatric population.

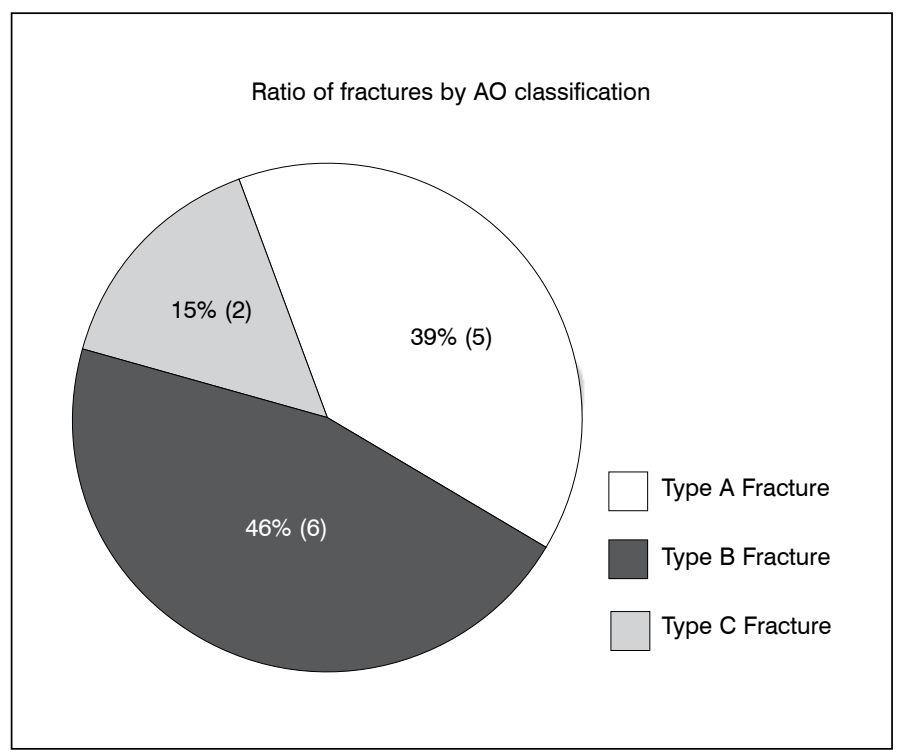

Figure 3. Patients with thoracolumbar fracture classified by the AO system.

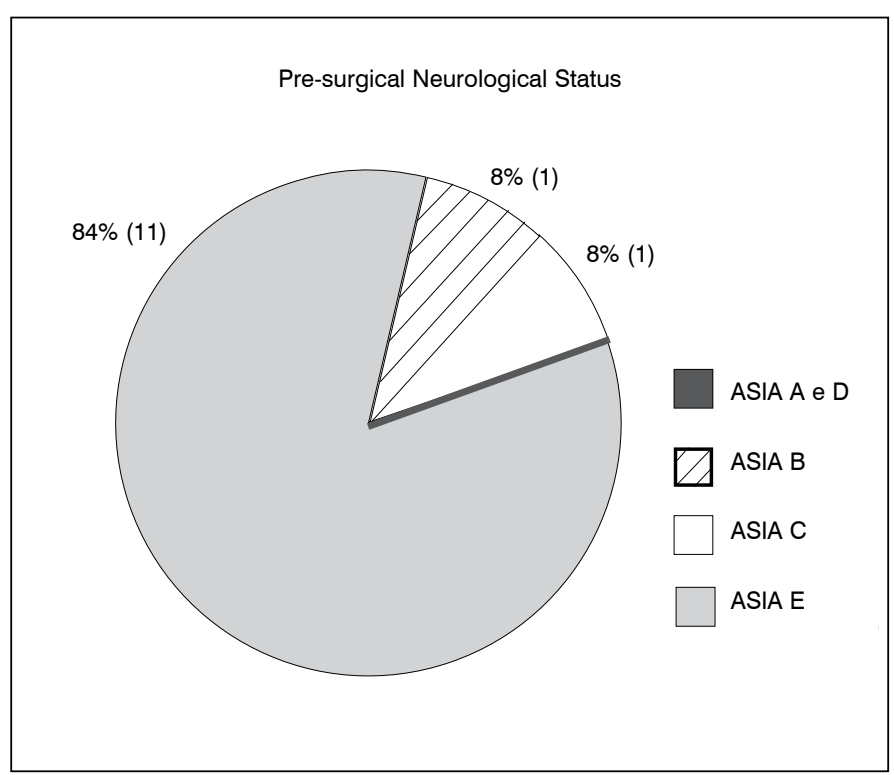

Figure 4. Pre-surgical neurological status of the patients, determined by the ASIA classification system (Standard Neurological Classification of Spinal Cord Injury of the American Spinal Injury Association). 
The use of a cross-link for bar union proved unnecessary in all but one patient with thoracolumbar fracture-dislocation at T12-L1 (thoracolumbar junction, thoracic vertebra number 12 , lumbar vertebra number 1) AO type C. 38\% of patients underwent surgery less than 24 hours after the accident, while another $62 \%$ underwent surgery after 24 hours but within less than 48 hours.

The neurological status of the patients improved after surgery, and $96 \%$ of patients achieved a neurological status classified as ASIA E (23 patients), while $4 \%$ achieved a neurological status of ASIA D (1 patient).

All the patients used a corset during postsurgical recovery, while 23 patients used a Jewett corset and 1 patient a high Taylor corset for 3 months.

Fracture healing occurred in 2.8 months on average. The patients underwent arthrodesis through iliac crest graft (4 patients), synthetic graft (2 patients), or no graft (7 patients). (Figure 5)

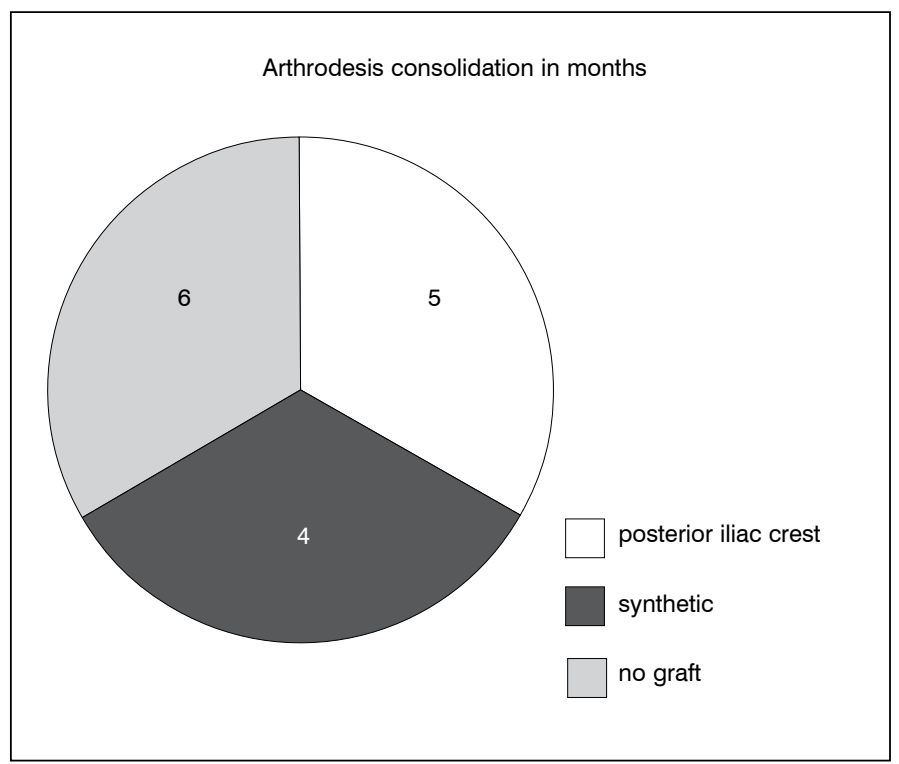

Figure 5. Consolidation of arthrodesis in months, using iliac crest graft, synthetic graft and no graft.

No pseudoarthrosis was found in any patient, neither was there any delay in consolidation. The patients did not present with any postsurgical deformities or infections. $8 \%$ of the population (only 1 patient) had to undergo implant repositioning using a single screw invading the vertebral canal. The instrumentation of the thoracolumbar fracture was removed in 38\% (5 of the patients), at an average time of 12.2 months after surgery. The cause was not leaving the instrumentation in the correct place.

\section{REFERENCES}

1. Santiago R, Guenther E, Carroll K, Junkins EP Jr. The clinical presentation of pediatric thoracolumbar fractures. J Trauma. 2006;60(1):187-92.

2. Reddy SP, Junewick JJ, Backstrom JW. Distribution of spinal fractures in children: does age, mechanism of injury, or gender play a significant role? Pediatr Radiol. 2003;33(11):776-81

3. Junkins EP Jr, Stotts A, Santiago R, Guenther E. The clinical presentation of pediatric thoracolumbar fractures: a prospective study. J Trauma. 2008:65(5):1066-71.

4. Buldini B, Amigoni A, Faggin R, Laverda AM. Spinal cord injury without radiographic abnormalities. Eur J Pediatr. 2006;165(2):108-11.

5. Tran B, Silvera M, Newton A, Kleinman PK. Inflicted T12 fracture-dislocation: CT/MR correlation and mechanistic implications. Pediatr Radiol. 2007;37(11):1171-3.

6. Levin TL, Berdon WE, Cassell I, BlitmanNM. Thoracolumbar fracture with listhesis-an uncommon manifestation of child abuse. Pediatr Radiol. 2003;33(5):305-10.

7. Bosch PP, VogtMT, Ward WT. Pediatric spinal cord injury without radiographic abnormality (SCIWORA): the absence of occult instability and lack of indication for bracing. Spine (PhilaPa 1976). 2002;27(24):2788-800.

8. Mulpuri K, Jawadi A, Perdios A, Choit RL, Tredwell SJ, Reilly CW. Outcome analysis of chance fractures of the skeletally immature spine. Spine (PhilaPa 1976). 2007;32(24):E702-7.

\section{DISCUSSION}

Unstable fractures of the thoracolumbar spine in the pediatric population are relatively rare. In 16 years of follow-up of our study, only 24 surgeries were performed on pediatric patients with thoracolumbar fracture.

Pediatric patients aged 9-14 years presented with thoracolumbar fractures most often, as is also reported in the international literature. ${ }^{11}$

Accidents are the most common cause of mechanism of injury of thoracolumbar fractures in the pediatric population, while falls from a height are the most common cause. This differs from the international literature, in which car accidents are reported as the main cause..$^{1-3,12}$

Thoracolumbar fracture-dislocation is a serious injury that is presented in the study. Despite the extensive musculoskeletal injury, complete spinal cord injury was not present, since the cases reported in the literature describe it as a serious $\mathrm{SCl}{ }^{12}$

The most common fracture-dislocation anatomical sites were the thoracolumbar junction (T12-L1) and the lumbar region (L3-L4)..$^{13.14}$

The integrity of the neurological system (ASIA E) was found most frequently in our pediatric patients, as this is no established correlation of the size of the fragment in the spinal canal and the type of spinal cord injury established in the patient, in cases of $\mathrm{SCl}$ injury in fractures. ${ }^{15}$

The pediatric spine did not suffer deformities of the thoracolumbar region in the long-term postsurgical outcome with follow-up of 36 months, as treatment of thoracolumbar fractures in the international literature is highly controversial. ${ }^{16}$

\section{CONCLUSION}

Adolescents are the patients at greatest risk of sustaining a thoracolumbar fracture in the pediatric population, while falls from heights are the most common cause in this population. The thoracolumbar junction is the most frequently injured anatomical site (T12-L1), while neurological damage in this type of fracture is rare in the pediatric population.

Surgical treatment should be performed by surgeons trained in handling instruments such as small-diameter $(5 \mathrm{~mm})$ transpedicular screws, as well as pedicle or laminar hooks, as the thoracolumbar spine in the pediatric population has anatomical morphology in musculoskeletal development and small anatomical structures.

Pseudoarthrosis of thoracolumbar fractures is rare in the pediatric population, as are structural deformities following surgical instrumentation.

All authors declare no potential conflict of interest concerning this article.
9. Thomas KC, Lalonde F, O'Neil J, LettsRM. Multiple-level thoracolumbar burst fractures in teenaged patients. J PediatrOrthop. 2003;23(1):119-23.

10. Parisini P, Di Silvestre M, Greggi T. Treatment of spinal fractures in children and adolescents: long-term results in 44 patients. Spine (PhilaPa 1976). 2002 Sep;27(18):1989-94.

11. Clark P, Letts M. Trauma to the thoracic and lumbar spine in the adolescent. Can J Surg. 2001:44(5):337-45

12. Sieradzki JP, Sarwark JF. Thoracolumbar fracture-dislocation in child abuse: case report, closed reduction technique and review of the literature. Pediatr Neurosurg. 2008;44(3):253-7.

13. Wood K, Buttermann G, MehbodA, Garvey T, Jhanjee R, Sechriest V. Operative compared with nonoperative treatment of a thoracolumbar burst fracture without neurological deficit. A prospective, randomized study. J Bone Joint Surg Am. 2003;85-A(5):773-81.

14. Weninger $\mathrm{P}$, Schultz $\mathrm{A}$, Hertz $\mathrm{H}$. Conservative management of thoracolumbar and lumbar spine compression and burst fractures: functional and radiographic outcomes in 136 cases treated by closed reduction and casting. Arch Orthop Trauma Surg. 2009;129(2):207-19.

15. Mohanty SP, BhatNS, Abraham R, Ishwara Keerthi C. Neurological deficit and canal compromise in thoracolumbar and lumbar burst fractures. J Orthop Surg (Hong Kong). 2008;16(1):20-3

16. Kong L, Wang W. Thoracolumbar fractures. Eur Spine J. 2007;16(10):1737. 